Chagas (2018)

Gestão e Efetividade do PNAGE: A Experiência de Modernização /No Estado de Sergipe em Análise

\title{
GESTÃO E EFETIVIDADE DO PNAGE: A EXPERIÊNCIA DE MODERNIZAÇÃO /NO ESTADO DE SERGIPE EM ANÁLISE
}

\author{
MANAGEMENT AND EFFECTIVENESS OF PNAGE: THE EXPERIENCE OF \\ MODERNIZATION IN THE STATE OF SERGIPE UNDER ANALYSIS
}

\section{GESTIÓN Y LA EFECTIVIDAD DE PNAGE: LA EXPERIENCIA DE LA MODERNIZACIÓN EN EL ESTADO DE SERGIPE BAJO ANÁLISIS}

\author{
Rosiane Chagas \\ Professora Associada 1 da Faculdade de Economia, Administração e Ciências Contábeis \\ (FEAC/UFAL) \\ Doutora em Administração pela Escola de Administração da Universidade Federal da Bahia \\ Email: rc@ @ feac.ufal.br
}

\begin{abstract}
RESUMO
O Programa Nacional de Apoio à Modernização da Gestão e do Planejamento dos Estados e do Distrito Federal (PNAGE) foi um esforço de reforma administrativa coordenada pelo governo federal, voltado à modernização de estruturas e processos dos governos estaduais. O objetivo geral deste artigo é compreender como o PNAGE se processa em Sergipe; o que se desdobra nos seguintes objetivos específicos: (1) caracterizar o PNAGE a partir da governança pública em termos de gestão e efetividade; e (2) analisar a gestão e a efetividade do PNAGE em Sergipe. Aborda-se o PNAGE em termos de governança pública e particularmente de gestão e efetividade, e com base nessa abordagem desenvolve-se a análise do PNAGE em Sergipe. Para essa análise, realizou-se uma pesquisa qualitativa tendo como método o estudo de caso subsidiado por pesquisa documental e entrevista. Verificou-se nessa análise que o governo de Sergipe apresentou avanços pontuais em relação às seis áreas de atuação do PNAGE e seus produtos finais, localizados em projetos de secretarias específicas. A partir dessa análise, conclui-se que a modernização no âmbito do governo estadual de Sergipe como um todo ainda está longe de se concretizar em termos de gestão e efetividade.

Palavras-chave: Governança Pública. Modernização. PNAGE. Gestão. Efetividade.
\end{abstract}

\begin{abstract}
The National Program to Support the Modernization of Management and Planning of the States and the Federal District (PNAGE) was an administrative reform effort coordinated by the federal government, aimed at modernizing structures and processes of state governments. The general objective of this article is to understand how PNAGE is carried out in Sergipe; which is broken down into the following specific objectives: (1) to characterize PNAGE from public governance in terms of management and effectiveness; and (2) analyze the PNAGE in Sergipe. PNAGE is approached in terms of public governance, particularly management and effectiveness, and based on this approach the analysis of PNAGE in Sergipe is developed. For this analysis, a qualitative research was carried out using a case study subsidized by documentary research and interview. It was verified in this analysis that the government of Sergipe presented specific advances in relation to the six areas of PNAGE performance and its final products, located in projects of specific secretaries. From this analysis, it is concluded
\end{abstract}


Chagas (2018)

Gestão e Efetividade do PNAGE: A Experiência de Modernização /No Estado de Sergipe em Análise

that the modernization within the state government of Sergipe as a whole is still far from being realized in terms of management and effectiveness.

Keywords: Public Governance. Modernization. PNAGE. Management. Effectiveness.

\section{RESUMEN}

El Programa Nacional de Apoyo a la Modernización de la Gestión y Planificación de los Estados y el Distrito Federal (PNAGE) fue un esfuerzo de reforma administrativa coordinado por el gobierno federal, destinado a modernizar las estructuras y procesos de los gobiernos estatales. El objetivo general de este artículo es comprender cómo se realiza PNAGE en Sergipe; El cual se desglosa en los siguientes objetivos específicos: (1) caracterizar el PNAGE de la gobernanza pública en términos de gestión y efectividad; y (2) analizar el PNAGE en Sergipe. Se aborda el PNAGE en términos de gobernanza pública y particularmente de gestión y efectividad, y con base en ese enfoque se desarrolla el análisis del PNAGE en Sergipe. Para ese análisis, se realizó una investigación cualitativa teniendo como método el estudio de caso subsidiado por investigación documental y entrevista. En este análisis se verificó que el gobierno de Sergipe presentó avances puntuales en relación a las seis áreas de actuación del PNAGE y sus productos finales, ubicados en proyectos de secretarías específicas. A partir de ese análisis, se concluye que la modernización en el ámbito del gobierno estatal de Sergipe como un todo todavía está lejos de concretarse en términos de gestión y efectividad.

Palabras clave: Gobernanza Pública. La Modernización. PNAGE. Gestión. Efectividad.

\section{INTRODUÇÃO}

O Programa Nacional de Apoio à Modernização da Gestão e do Planejamento dos Estados e do Distrito Federal (PNAGE) foi elaborado nos moldes do Programa Nacional de Apoio à Administração Fiscal para os Estados Brasileiros (PNAFE), como mais uma tentativa do governo federal de promover a modernização institucional e administrativa da gestão estadual. Desta feita, a partir de uma visão mais geral do ciclo da gestão pública, procurando atuar na integração das diferentes esferas de governo, seguindo os preceitos e orientações do Banco Interamericano de Desenvolvimento (BID), quanto ao compartilhamento de iniciativas, experiências de inovações e soluções de modernização no âmbito das administrações estaduais e entre diferentes estados da federação (ABRUCIO; GAETANI, 2006; MPOG, 2013a; 2013b).

Na fase de elaboração do PNAGE, entre os anos de 2003 e 2004, foi realizada uma pesquisa junto às administrações públicas estaduais para identificar quais os principais projetos inseridos no Planejamento Plurianual (PPA) e as principais deficiências e lacunas no âmbito da modernização da gestão e do planejamento. Esta pesquisa resultou em um diagnóstico sobre a situação administrativa dos governos estaduais brasileiros, indicando áreas prioritárias de investimento em modernização da gestão e do planejamento, considerando a eficiência na aplicação dos recursos financeiros do programa e a articulação das ações modernizantes dos governos federal e estaduais e destes entre si.

A lógica de elaboração do PNAGE pressupõe a integração entre o planejamento, o orçamento público, os recursos humanos e os sistemas de comunicação e informação para 
Gestão e Efetividade do PNAGE: A Experiência de Modernização /No Estado de Sergipe em Análise

melhoria do desempenho dos governos estaduais via instrumentos e ferramentas que viabilizem a sua boa execução e avaliação da efetividade na condução das metas previstas pelo programa e de interesse público.

Entretanto, questiona-se a condição dos governos estaduais em aderir, executar e avaliar o PNAGE, o que exigiria capacidade econômico-financeira para a contratação de empréstimo e equipe técnica qualificada para a coordenação administrativa e financeira do programa. Essas condições variam de estado para estado, em função das diferenças no âmbito institucional e administrativo de seus governos. O que se questiona no presente estudo, é como o PNAGE foi executado pelos diferentes governos estaduais.

Dentre os estados que aderiram ao programa, destaca-se aqui Sergipe, questionando-se particularmente como o PNAGE foi processado nesse estado em termos de gestão e efetividade. Define-se como objetivo geral deste artigo compreender como o PNAGE se processa em Sergipe; o que se desdobra nos seguintes objetivos específicos: (1) caracterizar o PNAGE a partir da governança pública em termos de gestão e efetividade; e (2) analisar a gestão e a efetividade do PNAGE em Sergipe.

Caracteriza-se o PNAGE como esforço de reforma administrativa voltado para a modernização dos governos estaduais em termos de governança pública, entendida aqui como aprimoramento do modelo gerencial, o que se desdobra em gestão e efetividade. A partir dessa caracterização, analisa-se a gestão (estruturas e processos) e a efetividade (atingimento das metas dos projetos indicados) do PNAGE em Sergipe.

A relevância deste estudo está na constatação de que a modernização de estruturas e processos no âmbito dos governos estaduais vem se tornando imprescindível para a ampliação dos mecanismos de governança, substituindo-se os modelos arcaicos de gestão e as práticas burocráticas obsoletas, além de contribuir na melhoria da qualidade dos serviços públicos. $\mathrm{O}$ caminho para a modernização estadual ainda é longo e carece de estudos que avancem na análise de publicações sobre o tema, oferecendo informações relevantes sobre os programas de modernização no âmbito dos governos estaduais.

Este artigo está divido em cinco seções. (1) Introdução, na qual são apresentados tema, problema, objetivos, estratégia metodológica e estrutura do artigo; (2) Governança Pública, gestão e efetividade, que consistem em um referencial teórico composto de (2.1) Governança pública como aperfeiçoamento do modelo gerencial e (2.2) Governança pública como gestão e efetividade; (3) Procedimentos metodológicos, na qual são apresentados a estruturação da análise do PNAGE em Sergipe e o delineamento da pesquisa que subsidiou essa análise; (4) Gestão e efetividade do PNAGE em Sergipe, na qual é apresentada a análise do programa nesse estado; e (5) Conclusão, na qual são apresentadas as considerações finais do artigo.

\section{GOVERNANÇA PÚBLICA, GESTÃO E EFETIVIDADE}

\subsection{Governança Pública como Aperfeiçoamento do Modelo Gerencial}

O tema governança pública vem despertando interesse da comunidade acadêmica e das instituições públicas desde a década de 1990, em grande parte pela preocupação em compreender as práticas gerenciais modernas no âmbito da administração pública com vistas a excelência na prestação de serviços públicos. Ketll (2005) afirma que, durante as últimas décadas, uma série de reformas tem sido implantada na gestão pública em todo o mundo. A motivação da maioria dos governos para reformar e modernizar tem sido a busca pela melhoria na qualidade dos serviços públicos. 
O movimento de reforma incluiu uma série de inovações organizacionais, muitas vezes resumidas sob o rótulo da New Public Management (HANSEN, 2011). Buscava-se, com isso, o aumento da eficiência e efetividade do setor público e maior responsabilização das agências governamentais frente aos clientes e consumidores do serviço público.

Nestes termos, pode-se afirmar que a NGP e a governança pública são apresentadas como sinônimos, tratando-se de uma evolução do termo (BRESSER-PEREIRA, 2000; HAQUE, 2004). De acordo com Bovaird e Loeffler (2003), a governança pública volta-se não apenas para a qualidade dos serviços públicos, como também para a qualidade de vida do cidadão, indicando o aprimoramento da gestão em função da efetividade.

Em um estudo que fizeram em dez países, Pollitt e Bouckaert (2011) encontraram fortes evidências das diferenças nacionais e de como estas influenciaram na adoção dos preceitos da NGP. Buscou-se então adaptá-la, de forma quase individual, às especificidades para produzir proposições de caminhos diversificados com histórias e trajetórias próprias que objetivam responder aos desafios de cada nação.

No Brasil, o campo da administração pública tem dado relativa atenção aos movimentos de reforma via programas governamentais de modernização, que se dedicam, em tese, à reorganização das estruturas e dos processos e pouco ao aprofundamento da teoria sobre as mudanças e inovações geradas por tais esforços. Assim, do ponto de vista das pesquisas e estudos teóricos sobre a administração pública, os avanços não têm acompanhado essa evolução, nem refletem a importância desse campo de conhecimento (FADUL; SILVA, 2009).

Em outra perspectiva Rezende (2004, p. 125) destaca que:

Ao que tudo indica, as reformas administrativas são pensadas de forma fragmentada e recorrentes no propósito de melhorar o funcionamento da administração pública e a qualidade na prestação dos serviços públicos, porém, repetem os mesmos erros no combate aos velhos e persistentes problemas de controle e desempenho do aparato burocrático.

A governança pública como aperfeiçoamento da NGP favorece a criação de estratégias de atuação de governos e instituições públicas e de mecanismos e instrumentos de responsabilização para resultados efetivos e sustentáveis. Outro aspecto importante é a entrada de novas tecnologias e inovação em estruturas e processos com vistas à ampliação e melhor utilização de ferramentas técnicas para assegurar a eficiência, eficácia e efetividade interna e externa, através de práticas modernas de gestão, indispensáveis na melhoria do desempenho dos serviços prestados pelos agentes públicos.

Com isso, evidencia-se a necessidade de continuidade de esforços de modernização para a redefinição de modelos de gestão com vistas a melhor capacidade de coordenação intersetorial das ações governamentais. A divisão da estrutura governamental em departamentos, setores ou seções, com base na abordagem tradicional da administração, tem provocado um conjunto de práticas isoladas, fragmentadas e que em alguns casos são replicadas, gerando custo elevado pelo retrabalho, ineficiência e pouca ou nenhuma efetividade no atendimento às demandas do cidadão (GARNIER, 2005; GOMES, 2009).

Subirats (1993) ressalta que o processo de implantação de políticas públicas e programas governamentais envolvem atores de diferentes níveis governamentais e organizações com distintos interesses, expertises e formas institucionais, constituindo arranjos 
Gestão e Efetividade do PNAGE: A Experiência de Modernização /No Estado de Sergipe em Análise

Inter organizacionais e Inter setoriais para a consecução de ações governamentais específicas, sendo que a sua estrutura e formas de interação influenciam em seu desempenho.

O termo "governança pública" vem sendo apresentado no âmbito acadêmico e na prática das instituições públicas com vários significados. $\mathrm{Na}$ ausência de um conceito universal, a ideia que prevalece na presente pesquisa é a de que a governança pública deve ser entendida como um conjunto de preceitos que sinalizam para o aperfeiçoamento do modelo gerencial, buscando suplantar as práticas burocráticas obsoletas, com ênfase na eficiência, gestão por resultados, avaliação da qualidade e efetividade das ações do setor público.

De acordo com Fernandes e Outros (2015) Outro elemento muito importante foi a orientação básica constante no bojo conceitual da Nova Gestão Pública, segundo a qual seria impossível reinventar o governo de baixo para cima, devido ao seu tamanho, sendo aconselhável que a reforma fosse implementada em nível federal, acreditando-se que seria irradiada naturalmente para os estados (seguindo o modelo top-down).

\subsection{Governança Pública como Gestão e Efetividade}

$\mathrm{Na}$ experiência de reforma administrativa, alguns países se tornaram referências pontuais para o resto do mundo. No caso dos Países Baixos, buscou-se garantir que o objetivo estratégico de melhorar a governança, continuasse a receber a atenção de todas as lideranças do governo e demais públicos de interesse, como fornecedores, parceiros e a sociedade (TIMMERS, 2000).

Na recente estratégia de modernização do governo central em Moçambique, o tema, reformas administrativas, adquiriu centralidade crescente no debate sobre as condições para o enfrentamento dos problemas estruturais e das fragilidades institucionais da gestão pública, caracterizada por uma burocracia excessiva e inoperante, pouco flexível e dinâmica. Dentre as mudanças efetuadas destaca-se a implementação de um conjunto de princípios e práticas de gestão pública, voltadas a maior accountability e a avaliação por resultados (SIMIONE, 2014).

De acordo com Nader (2005), foi a partir do PPA 2000-2003, denominado Programa Avança Brasil, que se introduziu na administração pública brasileira, de maneira institucionalizada, um ciclo de gestão composto pelas atividades de planejamento, monitoramento, avaliação e revisão dos programas e do PPA com o propósito de orientar o gasto público por resultados para a sociedade. Ainda se procurou desenvolver uma cultura de controles gerenciais e de avaliação em três dimensões da ação governamental: a eficiência, a eficácia e a efetividade.

Sano e Montenegro Filho (2013) assegura que o motivo que justifica o crescente interesse da gestão pública pela avaliação de programas e projetos seria a preocupação com a efetividade, isto é, com a verificação dos resultados esperados e não esperados alcançados com a execução de programas e projetos governamentais. Entretanto, Costa e Castanhar (2003) ressaltam que é comum a confusão entre os conceitos de efetividade e eficácia. Uma forma de reduzir as dúvidas é verificar se o indicador aponta para impactos ou efeitos nos resultados do programa sobre o público-alvo.

Cohen e Franco (2004) apresentam definições sobre o assunto. Para esses autores, eficácia é a relação entre alcance de metas e tempo ou, em outras palavras, é o grau em que se alcançam os objetivos e metas do programa, em um determinado período de tempo, sem considerar os custos implicados; eficiência é a relação entre custo e benefícios, na qual se busca a minimização do custo total para uma quantidade de produto, ou a maximização do 
produto para um gasto total previamente fixado. Efetividade é a relação entre os resultados e os objetivos, isto é, a medida do impacto ou do grau de alcance dos objetivos.

Em muitas situações o conceito de efetividade interna é utilizado como sinônimo de eficácia. Esta última refere-se ao grau de consecução dos objetivos estabelecidos pela gestão, ao passo que a eficiência refere-se à quantidade, tipo, custo e qualidade dos recursos utilizados para atingir esses objetivos.

Sobre o conceito de efetividade interna, pode-se afirmar aqui, a partir das premissas apresentadas pelos autores, que como conceito operacional para o trabalho, se refere à comparação dos resultados alcançados em relação aos resultados previstos pelo PNAGE. Isto reforça a ideia de que os instrumentos e ferramentas de monitoramento e avaliação deveriam ser internalizados na gestão pública, na busca de melhoria contínua para ações governamentais mais inovadoras e proativas.

\section{PROCEDIMENTOS METODOLÓGICOS}

Para analisar o PNAGE em Sergipe, utilizou-se o referencial teórico apresentado sucintamente na seção anterior. Ele foi construído em função do conceito de governança pública como aperfeiçoamento do modelo gerencial, desdobrado em duas dimensões de análise: gestão e efetividade. Da dimensão gestão extraíram-se as categorias reestruturação organizacional e administrativa. Da dimensão efetividade extraiu-se a categoria efetividade interna no grau de atingimento dos objetivos previstos.

Além disso, o estudo em tela caracteriza-se como exploratório e descritivo quanto ao objetivo, como qualitativo quanto à problemática e, em relação aos procedimentos utilizou-se o método de pesquisa definido como estudo de caso, por permitir ao investigador um aprofundamento em relação ao fenômeno estudado, revelando-se nuance difíceis de serem enxergadas "a olho nu" (YIN, 2005). O objeto de estudo, nesse caso, foi o PNAGE no estado de Sergipe. As informações, portanto, apresentaram-se predominantemente qualitativas, tanto no levantamento por meio de pesquisa documental e entrevista, quanto na análise de conteúdo.

Consultaram-se os principais documentos do PNAGE, a saber: apresentação e descrição do programa disponível na web: Ministério do Planejamento, Orçamento e Gestão (MPOG)/Programas e Projetos de Gestão/PNAGE; comunicados para as Unidades de Coordenação Estaduais (UCEs); manual de execução do PNAGE; relatórios semestrais de progresso (situação geral do programa; execução física e financeira e aquisições e contratações) do governo estadual de Sergipe (2006; 2010; 2012a; 2013a; e 2013c) e ainda o relatório final do PNAGE (2013b).

Consultaram-se também os relatórios em forma de artigos publicados pelo Conselho Nacional de Secretários de Estado de Administração (CONSAD), nos quais são registradas as trajetórias do programa de alguns governos estaduais e da direção nacional do PNAGE, além de pesquisa survey publicada pelos coordenadores da UCE-RJ sobre o desempenho geral do programa nos seus dois primeiros anos, na percepção dos coordenadores e técnicos das UCEs (GUBERMAN; KNOPP, 2009, 2011; VASCONCELOS, 2010).

Para possibilitar uma análise mais criteriosa dos documentos do PNAGE, realizaramse duas entrevistas, em momentos distintos, com a coordenadora da UCE-SE e a secretária do programa, com vistas ao melhor entendimento da experiência de modernização estadual na perspectiva dos produtos finais. Elaborou-se o roteiro de entrevista com base no modelo de 
análise em governança pública, em função das dimensões de gestão mais especificamente, nas categorias de reestruturação organizacional e administrativa e da efetividade interna no grau de atingimento dos objetivos pretendidos pelo PNAGE-SE.

Entrevistaram-se coordenadora (E1) e a secretária do PNAGE-SE (E2). A escolha da coordenadora e secretária deveu-se à delimitação do objeto de estudo, voltado aos aspectos de gestão e efetividade do programa. Obtiveram-se os conteúdos por meio das entrevistas com questões abertas e escritos na íntegra, sem desprezar nenhuma fala, nenhuma "expressão" citada pelos entrevistados. Dando continuidade, procedeu-se a uma leitura minuciosa de todo o material. Após a leitura, separaram-se os conteúdos citados que respondiam de forma mais direta aos objetivos da pesquisa.

Analisaram-se os referidos conteúdos em função das dimensões gestão e efetividade e, mais especificamente, das categorias reestruturação organizacional e administrativa e efetividade interna no grau de atingimento dos objetivos pretendidos pelo PNAGE-SE. No desenvolvimento dessa análise de conteúdo, evidenciaram-se, ao lado de "gestão" e "efetividade", temas correlatos como "melhorias na gestão", "modernização", "indicadores" "avaliação" "contribuições" e "dificuldades".

\section{GESTÃO E EFETIVIDADE DO PNAGE EM SERGIPE-SE}

O valor total do investimento no PNAGE foi de US\$ 155 milhões, sendo US\$ 93 milhões de recursos do Bando Interamericano de Desenvolvimento (BID) e US\$ 62 milhões de contrapartida local dos governos estaduais e do MPOG (GUBERMAN; KNOPP; SENDIN, 2010). A elaboração e execução do PNAGE no âmbito dos governos estaduais representou o fortalecimento do CONSAD, o que ensejou o surgimento de iniciativas de cooperação entre governos estaduais, tendo como propósito a busca de ações compartilhadas, levando as experiências bem-sucedidas para outras localidades (COSTA; LANDIM, 2007).

A UCE-PNAGE/SE foi criada a partir do esforço da equipe da Secretaria do Planejamento e Gestão Pública (SEPLAG-SE), já que os recursos do convênio MPOG-BID destinados ao estado quase foram devolvidos por falta, no primeiro momento, da contrapartida do Tesouro estadual. A UCE-SE foi concebida com o propósito de gerir o programa de modernização que estava sendo implantado nos governos estaduais na época, por meio de um convênio com o MPOG e com recursos do BID. O montante de recursos destinados ao projeto do estado de Sergipe foi de US\$2.200.000, foi executado em cinco anos (2006 a 2011), prorrogado por mais dois, até 2013 (MPOG, 2013b).

A estrutura organizacional da UCE-PNAGE/SE foi inserida na SEPLAG-SE, e por dificuldades de quantitativo de pessoal qualificado para dar conta das demandas do programa, já iniciou com uma estrutura enxuta, restringindo, sobretudo, as funções de monitoramento e avaliação das ações executadas no estado. Os funcionários responsáveis pela execução do PNAGE-SE acumulavam outras responsabilidades na secretaria, o que implicou em uma sobrecarga de trabalho e atraso no atendimento das demandas.

Figura 1 - Organograma da UCE-PNAGE/SE 


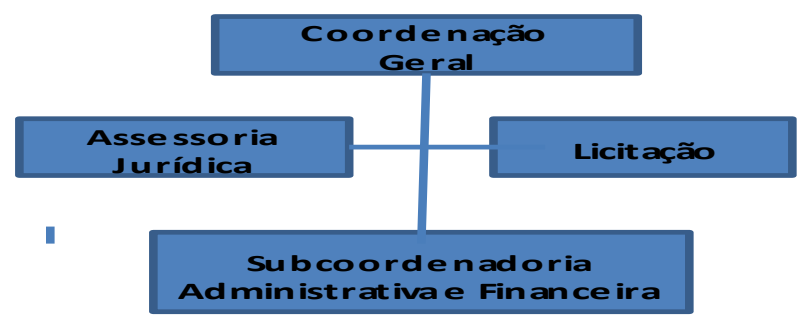

Fonte: Construção própria com base em; MPOG, 2006; MPOG, 2010; MPOG, 2012a.

O PNAGE-SE possibilitou a sensibilização e uma melhor compreensão para a necessidade de modernização da gestão e do planejamento no governo de Sergipe. Nesse período foi criada, em caráter permanente, a Superintendência Geral de Modernização da Gestão e do Atendimento ao Cidadão (SUMOGE) na SEPLAG-SE, que, além da responsabilidade de coordenar a execução do PNAGE-SE, assumiria o compromisso de ampliar as ações de modernização do governo e dar continuidade às ações do Programa que não fossem cumpridas no prazo estabelecido e com os recursos do BID.

A partir do PNAGE, a superintendência local busca fomentar de forma mais sistemática a cultura de modernização com outras iniciativas para a melhoria das atividades do governo como um todo, ainda muito aquém das necessidades do próprio governo, e da sociedade que clama por serviços públicos de qualidade. Tal realidade se confirma pela limitação de recursos humanos e financeiros, bem como pela ausência de ações contínuas que reafirmem o compromisso político e administrativo do governo com a modernização.

Os projetos executados pelo PNAGE-SE foram definidos com base nas prioridades do PPA do estado e orientados conforme as sete áreas de atuação, cujos componentes e subcomponentes foram financiados pelos recursos do Programa. Na Figura 2 são apresentados os componentes, objetivos e subcomponentes do PNAGE.

Inicialmente os estados participantes deveriam apresentar projetos nas sete áreas de atuação, posteriormente a coordenação nacional promoveu ajustes devido às condições de operacionalização de cada UCE.

Figura 2 - Componentes, Objetivos e Subcomponentes do PNAGE

\begin{tabular}{|l|l|}
\hline \multicolumn{1}{|c|}{ COMPONENTES/OBJETIVOS } & \multicolumn{1}{|c|}{ SUBCOMPONENTES FINANCIADOS PELO } \\
PNAGE
\end{tabular}


Chagas (2018)

Gestão e Efetividade do PNAGE: A Experiência de Modernização /No Estado de Sergipe em Análise

Buscará ampliar a disponibilidade e confiabilidade das informações operacionais e gerenciais de gestão de recursos humanos dos estados participantes; e (iv) - aperfeiçoamento dos atuais modelos de gestão de recursos humanos.

3. Modernização de estruturas organizacionais e de processos administrativos.

OBJETIVO: aumentar a efetividade e a eficiência dos processos de gestão e controle das administrações públicas dos estados participantes para modernizar suas estruturas organizacionais e seus processos administrativos. Buscará ampliar os controles sobre o gasto público em geral e sobre os custos operacionais e administrativos.

4. Fortalecimento dos mecanismos de
transparência administrativa e de comunicação.

OBJETIVO: Fortalecer os mecanismos de transparência administrativa e de comunicação dos estados participantes. Buscará influenciar positivamente a conduta ética dos servidores públicos e aumentar o controle social modernização da gestão de processos de logística (bens imóveis, aprovisionamento e convênios e contratos); (iii) - desenvolvimento da capacidade de gestão de custos; (iv) - modernização da gestão da memória administrativa; e (v) - aperfeiçoamento dos processos de controle interno e de sua vinculação com os processos de controle externo.

(i) - aperfeiçoamento dos mecanismos de comunicação com os servidores públicos dos estados participantes; (ii) - aperfeiçoamento dos mecanismos de monitoramento da conduta dos servidores públicos e de divulgação de valores éticos (ouvidorias); (iii) - fortalecimento das ouvidorias; (iv) - aperfeiçoamento das ações e da articulação dos órgãos de controle geral (corregedorias); (v) - fortalecimento dos mecanismos de participação e controle social; e (vi) - avaliação sistemática da prestação de serviços ao público.

5. Modernização da gestão da informação e integração dos sistemas de tecnologia de informação.

OBJETIVO: Aumentar a capacidade de gestão dos órgãos de planejamento dos estados participantes para melhorar a qualidade e efetividade da informação. Buscará ampliar a disponibilidade e confiabilidade das informações operacionais e gerenciais nas áreas de planejamento, gestão de recursos humanos, gestão de logística e avaliação de custos.

$\begin{aligned} & \text { 6. Desenvolvimento de uma cultura de promoção } \\ & \text { e implantação da mudança institucional. }\end{aligned}$
$\begin{aligned} & \text { OBJETIVO: Promover e implantar uma mudança } \\ & \text { institucional nas unidades de planejamento e a } \\ & \text { administração dos estados. }\end{aligned}$
$\begin{aligned} & \text { (i) desenvolvimento e sistematização de diagnósticos } \\ & \text { hebilidades de gestão para mudança institucional e (iii) - } \\ & \text { implantação de mecanismos de indução e de } \\ & \text { reconhecimento de mérito e desempenho individual e de } \\ & \text { equipe, bem como avaliação de mudança institucional. }\end{aligned}$
$\begin{aligned} & \text { 7. Apoio à cooperação em gestão. } \\ & \text { OBJETIVO: deste componente é fortalecer a } \\ & \text { capacidade de gestão dos estados participantes e } \\ & \text { incentivar a cooperação e o compartilhamento de } \\ & \text { soluções entre eles. }\end{aligned}$
$\begin{aligned} & \text { (i) - capacitação para gestão dos projetos; (ii) - } \\ & \text { desenvolvimento e implantação de metodologias, assim } \\ & \text { como de sistemas para gerenciamento, monitoramento e } \\ & \text { avaliação (SISMA/SGP); (iii) - formulação e } \\ & \text { implantação de soluções compartilhadas e (iv) - } \\ & \text { replicação de soluções cooperadas. }\end{aligned}$

Fonte: Adaptado de MPOG (2006; 2010); Vasconcelos (2010, p. 10).

Nota-se, na definição dos componentes, uma demasiada abrangência no que tange à necessidade de modernização a ser atendida pelo estado de Sergipe, atingindo quase todas as áreas primordiais do governo, suscitando ações governamentais contínuas e que extrapola a capacidade do programa em termos de recursos financeiros e prazo de execução. Percebe-se que a definição do PNAGE segue a mesma orientação de outras iniciativas, ocorridas no passado recente, sempre de cima para baixo sem a participação mais direta dos estados, o que

Revista de Gestão, Finanças e Contabilidade - v. 8, n. 1, p. 92-110, jan./abr. 2018 ISSN 2238-5320, UNEB, Salvador/BA 
enfatiza o seu caráter normativo, distantes da realidade vivida por cada estado nas suas particularidades. O que se coloca nos componentes é a exigência de que as ações sejam executadas pelos estados, com o fito de modernizar suas estruturas organizacionais e processos administrativos, dadas às mudanças que ocorrem no mundo, exigindo do governo estadual maior eficiência e efetividade nas suas ações, com accountability e transparência.

A urgência de reformas no aparelho de estado dos governos estaduais, particularmente, no âmbito de Sergipe, se faz necessária pelas enormes assimetrias entre os estados, não só pelas diferenças regionais, sobretudo, pelas dificuldades financeiras e de investimentos, que se caracterizam ainda por modelos de gestão arcaicos, demasiadamente burocráticos e com pouca inovação.

Figura 3 - Áreas, Projetos e Produtos Finais do PNAGE-SE

\section{COMPONENTES - ÁREAS DE ATUAÇÃO}

1. Fortalecimento da capacidade de planejamento e de gestão de políticas públicas
-Aperfeiçoamento da capacidade de formulação e implantação de políticas públicas.

- Gestão do Planejamento estadual estruturada. Uso de soluções tecnológicas compartilhadas/disponibilizadas entre estados. ERP (Enterprise Resource Planning), originário de Pernambuco e que hoje é utilizado por todos os órgãos da administração direta e indireta do estado de Sergipe e o EXPRESSO (sistema de webmail corporativo) originário do Paraná, atualmente usado por mais de 25.000 usuários, facilitando as comunicações institucionais no estado.

2. Desenvolvimento de políticas e da capacidade de gestão de recursos humanos

3. Modernização de estruturas organizacionais e de processos administrativos

- Plano de capacitação implantado. Criação da Escola de Segurança Pública e a Escola de Governo do Estado de Sergipe para realizar cursos, capacitações etc.

- Processos organizacionais e de RH redefinidos (estruturas organizacionais redesenhadas). Modernização da gestão de processos organizacionais, administrativos, operacionais e de logística a partir das seguintes ações: implantação em novembro de 2009 do sistema e-DOC para tramitação eletrônica de processos e documentos nos 58 órgãos do executivo estadual; formação de mais de 150 analistas de processo, servidores públicos, através da escola de governo; mapeamento de mais de 30 processos corporativos visando à desburocratização e a uma maior agilidade na prestação dos serviços públicos.

4. Fortalecimento de mecanismos de $\bullet$ Ouvidoria geral do estado e ouvidorias setoriais transparência administrativa e de comunicação implantadas. Etapa fundamental como auxílio para a implantação das rotinas impostas pela Lei de Acesso à Informação (LAI). 
Chagas (2018)

Gestão e Efetividade do PNAGE: A Experiência de Modernização /No Estado de Sergipe em Análise

\begin{tabular}{|l|l|l|}
\hline $\begin{array}{l}\text { 5. Modernização da gestão da informação e } \\
\text { integração dos sistemas de tecnologia de } \\
\text { Informação. }\end{array}$ & $\begin{array}{l}\text { - Modernização do parque tecnológico da SEPLAG, } \\
\text { implantado e cumprido parcialmente pela falta de recursos } \\
\text { suficientes e dificuldades no prazo dos processos licitatórios. } \\
\text { - Sistema de Gestão de Recursos Humanos implantado. Foi } \\
\text { operacionalizada uma solução de BI (Business Inteligence), } \\
\text { que permitiu uma análise proativa da folha do estado, } \\
\text { buscando-se a previsão do impacto das decisões } \\
\text { governamentais e a gestão mais adequada dos recursos com } \\
\text { pessoal. } \\
\text { Sistema de Gestão de Patrimônio (móvel e imóvel) } \\
\text { implantado no estado. Permitiu o acesso a informações de } \\
\text { utilização e estado de conservação de todos os prédios } \\
\text { públicos que integram o patrimônio do executivo estadual e } \\
\text { parte do quantitativo móvel. O sistema já se encontra } \\
\text { implantado em mais de } 34 \text { órgãos do executivo estadual. }\end{array}$ \\
\hline
\end{tabular}

Fonte: Construção própria com base no relatório final do PNAGE, MPOG (2013b).

Em relação à execução das ações do PNAGE pelo governo estadual de Sergipe, os produtos gerados na dimensão de gestão voltada à reestruturação organizacional e administrativa sugerem avanços pontuais na implantação de sistemas organizacionais e administrativos que, pelo que foi demonstrado, viabilizou de forma pontual algumas necessidades do governo quanto à desburocratização de alguns processos administrativos das secretarias de planejamento e da fazenda, oferecendo maior agilidade do ponto de vista interno. As ações indicaram algumas áreas de atuação do projeto que receberam maior atenção, enfatizando-se os componentes 1,3 e 5, e algumas ações ainda em fase inicial nos componentes 2 e 4.

Embora não tenham sido apresentadas na Figura 3, as ações vinculadas aos componentes 6 e 7, no relatório final do PNAGE (2013b), o estado de Sergipe inclui algumas ações relacionadas aos referidos componentes bem embrionárias, relativas à sensibilização que conseguiu realizar no período de vigência do programa. Na Figura 3, são descritas as ações que foram realizadas no prazo determinado pelo programa, e aquelas que foram cumpridas parcialmente. Entretanto, não foi apresentada de forma detalhada a situação das ações vinculadas aos componentes 6 e 7 que foram planejadas e não foram cumpridas no prazo de execução do PNAGE, bem como, a justificativa, de modo geral, indicando as razões pelas quais algumas ações planejadas dos componentes não foram executadas.

As limitações identificadas no relatório final do programa evidenciaram a necessidade de entrevistar a coordenadora e a secretária do PNAGE-SE em dois momentos distintos para melhor compreender os resultados alcançados pelo programa e sua contribuição na governança do estado.

$\mathrm{Na}$ primeira etapa da entrevista procurou-se atender a dimensão de gestão, especificamente sob a categoria reestruturação organizacional e administrativa.

A E1 destacou que:

[...] em Sergipe os recursos do BID foram liberados de uma só vez pelo atraso na disponibilidade da nossa contrapartida. Naquele período a contrapartida do Tesouro estadual era um problema, pois no momento da liberação não havia recursos orçamentários para isso. Foi preciso reanalisar o orçamento de forma minuciosa e estudar formas de conseguir os recursos necessários.

Ainda, segundo a E1:

Revista de Gestão, Finanças e Contabilidade - v. 8, n. 1, p. 92-110, jan./abr. 2018 ISSN 2238-5320, UNEB, Salvador/BA 
Chagas (2018)

Gestão e Efetividade do PNAGE: A Experiência de Modernização /No Estado de Sergipe em Análise

[...] a solução encontrada foi realocar recursos de outro projeto. Isso representou um esforço administrativo e, sobretudo, político, envolvendo o secretário de planejamento, governador e assembleia legislativa, que aprovou a mensagem do governador, solicitando a realocação dos recursos para a contrapartida. Pelas carências de recursos tanto financeiros como de pessoal, principalmente pela falta de mão de obra especializada, e ainda na experiência do estado, as melhorias foram mais voltadas ao ambiente interno de gestão.

A mesma argumentou:

[...] que no estado não houve tempo suficiente para se pensar em indicadores para avaliação do programa. No caso de Sergipe, foram devolvidos cerca de R\$ 400.000,00 do PNAGE, por problemas no andamento das licitações (um problema verificado na maioria dos estados), o que envolve vários órgãos, exigindo uma gama de procedimentos que, no geral, são extremamente burocratizados, mas mesmo assim o estado conseguiu realizar boa parte do que foi planejado.

Nessa direção, a E1 diz que "[...] isso ficou evidente nos depoimentos dados durante as reuniões do colegiado do PNAGE". Enfrentamos problemas de demora nas respostas pelo governo federal, que muitas vezes não documentava suas respostas; atrasos nos repasses dos recursos financiados; e falta de ferramenta de gestão única e integrada desde o início do programa, ocasionando retrabalho constante para o sistema informatizado de planejamento integrado ao sistema financeiro do estado, e que é alimentado por todos os órgãos, facilitando a integração das unidades de governo, beneficiando o melhor entendimento da importância estratégica do planejamento.

Definiram-se como orientação para os investimentos do programa em gestão, as políticas e modelos de gestão nas áreas de TI e logística, mas que ainda carecem de mais investimentos para sua efetiva implantação.

A E2 disse que:

[...] os esforços para reestruturação de alguns processos de trabalho favoreceram a melhoria dos serviços em setores pontuais do governo, do ponto de vista dos servidores, o que talvez ainda não seja percebido claramente pelo cidadão, pela falta, na maioria dos casos, de instrumentos efetivos de monitoramento, medição e avaliação.

Enquanto a E1 afirmou que:

Para fazer o acompanhamento, monitoramento e avaliação dos progressos do programa utilizou-se o SIGPNAGE (planilha Excel), que no início se resumia a acompanhar os gastos do PNAGE. Com a mudança na direção nacional do programa, em 2011, e com base nas propostas apresentadas pelas UCEs nas reuniões de progresso, a DN-PNAGE reformulou a planilha incluindo tópicos mais qualitativos que se destinariam a avaliar o programa, o que na prática não foi suficiente para garantir uma avaliação qualitativa das metas.

A E1 argumentou que:

Revista de Gestão, Finanças e Contabilidade - v. 8, n. 1, p. 92-110, jan./abr. 2018 ISSN 2238-5320, UNEB, Salvador/BA 
Gestão e Efetividade do PNAGE: A Experiência de Modernização /No Estado de Sergipe em Análise

[...] ao longo da execução do programa enfrentaram-se altos e baixos. No início, o sentimento era de não saber como agir frente a tantas demandas; a falta de experiência das equipes estaduais, principalmente no caso dos estados menores como Sergipe, e da própria DN-PNAGE se tornariam evidentes.

Ainda sobre a questão, a E2 disse que "[...] aos poucos fomos aprendendo, trocando informações nas discussões entre as UCEs e com a DN-PNAGE, e principalmente nas redes informais de relações construídas no decorrer da experiência”.

$\mathrm{Na}$ dimensão de efetividade, no que concerne a efetividade interna, no grau de atingimento dos objetivos previstos pelo Programa, a E1 disse que "É muito difícil modernizar as administrações públicas estaduais sem o estímulo, financiamento externo, coordenação e o monitoramento do governo federal".

Afirmou, ainda, que:

Para dar continuidade à política de modernização da gestão pública, parece ser fundamental a existência de um programa nos moldes do PNAGE, para sensibilizar e provocar os secretários, gestores (CONSAD, CONSEPLAN etc.), no sentido de criar as condições institucionais e operacionais para viabilizar os projetos locais de modernização. Transparência e accountability foram tratadas pelo programa de forma bem embrionária, os avanços foram poucos; isso envolve um esforço (relação estreita) maior e contínuo da gestão com os órgãos de controle externo do estado.

A E2 reforçou que:

[...] sem um programa sistematizado e coordenado pelo governo federal, torna-se praticamente impossível viabilizar a modernização administrativa de fato nos governos estaduais, sobretudo nos estados com menos recursos, pelos limites na disponibilidade de recursos físicos, financeiros e humanos, aspectos técnicos já citados e no político, principalmente, porque envolve autonomia e solução de continuidade para as ações do programa, entre outros.

A E1 registrou que:

[...] As ações modernizantes empreendidas no estado de Sergipe destinaram-se à implantação da Ouvidoria Geral do estado e do Código de Ética dos servidores públicos, que ainda carecem de outros investimentos para se consolidarem como ação efetiva do governo. No que tange às ações para a melhoria e ampliação dos mecanismos de controle social, participação do cidadão na gestão, o PNAGE não se dedicou a esses aspectos de forma específica.

Nessa direção, a E1 diz:

[...] Isso ficou evidente nos depoimentos dados durante as reuniões do colegiado do PNAGE. Enfrentamos problemas de demora nas respostas pelo governo federal, que muitas vezes não documentava suas respostas; atrasos nos repasses dos recursos financiados; e falta de ferramenta de gestão única e integrada desde o início do Programa, ocasionando retrabalho constante para o sistema informatizado de planejamento integrado ao sistema financeiro do estado, e que é alimentado por todos os órgãos, facilitando a integração das unidades de governo, beneficiando o melhor entendimento da importância estratégica do planejamento. Definiram-se

Revista de Gestão, Finanças e Contabilidade - v. 8, n. 1, p. 92-110, jan./abr. 2018 ISSN 2238-5320, UNEB, Salvador/BA 
Chagas (2018)

Gestão e Efetividade do PNAGE: A Experiência de Modernização /No Estado de Sergipe em Análise

como orientação as políticas e modelos de gestão nas áreas de TI e logística, mas que ainda carecem de mais investimentos para sua efetiva implantação.

No decorrer da execução, nas palavras da E1:

[...] buscou-se a troca de informações e atenção aos estados com maior dificuldade. A questão da modernização perpassa pela integração de estruturas e processos entre os vários setores e órgãos da administração estadual, coisa que ainda se configura em grande desafio para as próximas iniciativas (futuros programas) de modernização, o que depois do PNAGE se tornou um clamor geral pela continuidade de ações desse tipo.

A E1 disse que a efetividade enquanto grau de atingimento dos objetivos previstos pelo PNAGE

[...] pode ser considerada relativa, já que os mecanismos e instrumentos de monitoramento e avaliação do programa focaram mais nas metas físicas e financeiras e pouco nos indicadores qualitativos que contemplam a participação dos envolvidos (públicos, interno e externo), mesmo diante das alterações feitas no SIGPNAGE, planilha de acompanhamento financeiro das metas do programa, que em certa medida procurou ampliar e melhorar a avaliação com novos indicadores mais qualitativos para a medição de desempenho dos projetos e produtos finais, os avanços nesse aspecto foram poucos e carecem de aperfeiçoamento para novas propostas de modernização.

\section{A E2 reforçou que:}

Os indicadores de monitoramento e avaliação de desempenho do PNAGE-SE, foram definidos pelo governo federal e pelo BID. As cartilhas e os manuais de orientação e execução do PNAGE definiram esses indicadores. Os usuários (público interno) participaram na elaboração de termos de referência e definição de especificações das ações dos projetos estaduais e produtos, além do acompanhamento de consultorias e transferência de tecnologia.

A E1 enfatizou que:

[...] cada estado possui uma realidade particular, distinta e, por isso, os investimentos foram realizados de forma diferenciada. De forma geral, o ganho maior do programa foi quanto à prática de compartilhar sistemas de gestão nas áreas de tecnologia e de pessoal, ação cooperada entre os estados. A rede criada pelos técnicos envolvidos no programa ainda permanece ativa informalmente; as comunicações são feitas extraoficialmente para troca de experiências, soluções e informações. Seria interessante que o governo federal liderasse um movimento mais sistematizado para essas trocas entre os governos estaduais.

\section{A E1 afirmou ter}

[...] uma preocupação quanto à capacidade dos governos estaduais, particularmente o de Sergipe, de dar continuidade aos projetos de modernização executados parcialmente com os recursos do PNAGE, como prioridade de governo, a partir das condições presentes em cada realidade. $\mathrm{Na}$ visão da maioria dos coordenadores explicitadas nos encontros das UCEs, essa é uma questão delicada que depende de

Revista de Gestão, Finanças e Contabilidade - v. 8, n. 1, p. 92-110, jan./abr. 2018 ISSN 2238-5320, UNEB, Salvador/BA 
Chagas (2018)

Gestão e Efetividade do PNAGE: A Experiência de Modernização /No Estado de Sergipe em Análise

esforços políticos, o que na atual conjuntura não é possível prever o que pode acontecer. $\mathrm{O}$ fato é que o PNAGE gerou inquietação e significou uma oportunidade de sensibilização para a modernização da gestão estadual, o que a colocaria como algo imprescindível.

Segundo a E1:

A experiência de Sergipe demonstrou isso, quando da morte do governador Marcelo Deda. Mudou o governo, e depois disso passaram pela SEPLAG-SE três secretários em um curto espaço de tempo e mesmo assim se manteve a superintendente de modernização e a orientação de dar continuidade ao programa como prioridade, isso facilitou a continuidade das ações do PNAGE. Outros estados sofreram bastante pelas mudanças no governo e consequentemente nas secretarias (definição da modernização como prioridade para o estado de Sergipe e continuidade do programa).

E conclui dizendo que:

[...] em relação à coordenação do governo federal, a maior contribuição, foi o clima criado e permanentemente estimulado de troca e compartilhamento pelas reuniões frequentes e redes de informação que surgiam com mais intensidade a cada encontro promovido com os coordenadores e técnicos das UCEs, a exemplo do que já ocorria no nível estratégico, favorecendo o maior comprometimento do político e do administrativo com o programa e de forma mais ampla com a modernização da gestão pelos CONSAD e CONSEPLAN.

\section{CONCLUSÃO}

No bojo do esforço de mais uma vez viabilizar um programa de modernização de caráter institucional e administrativo na gestão estadual, o que se constata é a necessidade de perguntar até que ponto o PNAGE viabilizou a modernização dos governos estaduais, particularmente, na experiência do estado de Sergipe? Destacam-se como acertos do programa, a iniciativa de modernizar os governos estaduais e o fortalecimento do CONSAD que passa a ser fórum catalisador de propostas, inovações, compartilhamentos e troca de experiências da gestão pública estadual com vistas a sua melhoria interna.

Outro aspecto refere-se à oportunidade de captação de recursos financeiros, ainda que por empréstimo, gerada pelo programa, face as enormes dificuldades financeiras enfrentadas pelos governos estaduais. Os recursos disponibilizados para a modernização acabam servindo também para socorrer os governos estaduais em época de crise, o que vem se agravando a cada dia, mitigando a sua capacidade de investimento em melhorias nas estruturas e processos do governo em longo prazo.

A destinação e aplicação dos recursos do PNAGE, no caso de Sergipe, pela influência política do CONSAD e CONSEPLAN estimula a maior evidência das secretarias estaduais de administração e planejamento, responsáveis pela coordenação do programa, e em tese, beneficiários diretos dos recursos do programa, em detrimento das demais secretarias e órgãos do governo, ampliando assim as assimetrias já existentes em termos de gestão e efetividade.

Na definição dos componentes e subcomponentes do PNAGE, percebe-se a fragilidade na elaboração de um programa de modernização como esforço de reforma para todos os governos estaduais sem o entendimento das particularidades de cada estado. Nota-se um 
Chagas (2018)

Gestão e Efetividade do PNAGE: A Experiência de Modernização /No Estado de Sergipe em Análise

caráter eminentemente normativo, de cima para baixo, sem o conhecimento das especificidades que envolvem os governos estaduais, seus desafios, limitações e dificuldades.

A experiência do PNAGE-SE possibilita a criação de redes informais, com os demais governos estaduais o que enseja várias iniciativas de cooperação e compartilhamento, favorecendo assim na solução de problemas antigos e pontuais, como a reestruturação da gestão de planejamento, folha de pagamento, governo eletrônico e compras governamentais. Entretanto, grande parte dos projetos pretendidos com a execução do programa apenas iniciou-se, o que implica na necessidade do governo estadual em dar continuidade às ações com recursos próprios visando a sua conclusão para não perder os recursos já investidos.

Com efeito, o relatório final do PNAGE como se apresenta, evidencia muito mais a preocupação em atender as exigências dos agentes financeiros que garantem os repasses nos prazos definidos dos recursos financeiros, do que o monitoramento e avaliação qualitativa das metas alcançadas pelo programa.

A contribuição deste artigo resulta na melhor compreensão da proposta de modernização pretendida pelo PNAGE-SE, a partir das ações realizadas, no que concerne à gestão em termos de estruturas e processos e a efetividade no atingimento dos objetivos pretendidos pelo programa, considerando de forma sucinta as prováveis implicações dos resultados para a governança estadual.

Em suma, a proposta de modernização pretendida pelo PNAGE-SE introduz algumas melhorias pontuais nos processos e estruturas, sistemas administrativos no que concerne à folha de pagamento, compras governamentais e governo eletrônico, entretanto, a modernização não se concretiza como possibilidade de mudança no que se refere à gestão e efetividade, sugerindo a necessidade de novas pesquisas sobre o tema.

\section{REFERÊNCIAS}

ABRUCIO, F. L.; GAETANI, F. Avanços e perspectivas da gestão pública nos estados: agenda, aprendizado e coalizão. In: CONSAD. Brasília: CONSAD, 2006.

BOVAIRD, T.; LOEFFLER E. Evaluating the quality of public governance: indicators, models and methodologies. International Review of Administrative Science, v. 69, n. 3, p. 313-328, 2003.

BRESSER PEREIRA, L. C. A reforma gerencial do estado de 1995. Revista de Administração Pública, v. 34, n. 4, jul./ago. 2000.

COHEN, E.; FRANCO, R. Avaliação de projetos sociais. 6. ed. Petrópolis: Vozes, 2004.

COSTA, F. L.; LANDIM, M. C. Gestão pública nos governos subnacionais do Brasil: avanços, omissões e perspectivas. In: XII Congreso Internacional del CLAD sobre Reforma del Estado y de la Administración Pública, Sto. Domingo-República Dominicana, 30 out.-2 nov. 2007.

COSTA, F. L.; CASTANHAR, J. C. Avaliação de programas públicos: desafios conceituais e metodológicos. Revista de Administração Pública, Rio de Janeiro, v. 5, n. 37, p. 969-92, set./out. 2003. 
Chagas (2018)

Gestão e Efetividade do PNAGE: A Experiência de Modernização /No Estado de Sergipe em Análise

FADUL, É. M. C.; SILVA, M. A. M. Limites e possibilidades disciplinares da administração pública e dos estudos organizacionais. RAC, Curitiba, v. 13, n. 3, art. 1, p. 351-365, jul./ago. 2009.

FERNANDES, A. S. A, MORAES, D. B., NASCIMENTO, A. M. Reformas administrativas nos estados brasileiros: o caso da reforma administrativa do estado do Piauí. Cadernos Gestão Pública e Cidadania, São Paulo, 20 (67): 194-213, 2015.

GARNIER, L. Informe de Conclusiones. Área Temática: Fortalecimiento de la cooperación y la coordinación gubernamentales. In: X Congreso Internacional Del CLAD, sobre la reforma del Estado y de la administración pública. Santiago, 2005.

GOMES, E. G.M. Gestão por resultados e eficiência na administração pública: uma análise a luz da experiência de Minas Gerais. São Paulo, 2009. 187 f. Tese (Doutorado em Administração). EBAPE/FGV, São Paulo, 2009.

GUBERMAN, G.; KNOPP, G. Monitorar a prática para aprimorar o que se aprende: examinando sistemas internacionais de M\&A como benchmarking para a experiência brasileira. Revista Brasileira de Monitoramento e Avaliação, n. 2, p. 76-99 jul./dez. 2011.

GUBERMAN, G.; KNOPP, G. Modernizando a modernização da gestão: o que a experiência do PNAGE nos ensina. In: Congresso CONSAD de Gestão Pública. Anais eletrônicos... Brasília: CONSAD, 2009. Disponível em: http://consadnacional.org.br/wpcontent/uploads/2013/02/MODERNIZANDO-A-MODERNIZA\%C3\%87\%C3\%83O-DAGEST\%C3\%83O-O-QUE-A-EXPERI\%C3\%8ANCIA-DO-PNAGE-NOS-ENSINA.pdf. Acesso em: 21 jun. 2014.

GUBERMAN, G.; KNOPP, G.; SENDIN, Lília. [RE] Pensar, [RE] Agir, [INTER] Agir: a trajetória do PNAGE no estado do Rio de Janeiro. In: Congresso CONSAD de Gestão Pública III, 2010. Anais eletrônicos... Brasília: CONSAD, 2010. Disponível em:

http://www.escoladegestao.pr.gov.br/arquivos/File/Material_\%20CONSAD/paineis_III_congr esso_consad/painel_31/a_trajetoria_do_pnage_no_estado_do_rio_de_janeiro.pdf. Acesso em: 10 jul. 2015.

HANSEN, M. B. Antecedents of organizational innovation: the diffusion of new public management into danish local government. Public Administration, v. 89, n. 2, p. 285-306, 2011.

HAQUE, M. S. Governance and bureaucracy in Singapore: contemporary reforms and implications. International Political Science Review, v. 25, n. 2, p. 45-68, 2004.

KETLL, D. F. The Global Public Management Revolution. Washington: Brookings Institutions, 2005.

MPOG. Relatório de progresso do PNAGE, 2013a. Disponível em:

http://www.planejamento.gov.br/assuntos/gestao-publica/programas-e-projetos-degestao/apresentacao. Acesso em: 8 nov. 2013. 
MPOG. Relatório final do PNAGE: cumprimento de objetivo consolidado, 2013b. Disponível em: http://www.planejamento.gov.br/assuntos/gestao-publica/programas-eprojetos-de-gestao/apresentacao. Acesso em: 14 fev. 2014.

MPOG. Quadro IV- Demonstrativo de gastos por componente do PNAGE, 2013c. Disponível em: http://www.planejamento.gov.br/assuntos/gestao-publica/programas-eprojetos-de-gestao/apresentacao. Acesso em: 12 mar.2014.

MPOG. Relatório de Progresso do PNAGE. Brasília, 2012a. Disponível em: http://www.planejamento.gov.br/assuntos/gestao-publica/programas-e-projetos-degestao/apresentacao. Acesso em: 19 out.2014.

MPOG. Manual de Execução do PNAGE. Brasília, 2010. Disponível em: http://www.planejamento.gov.br/assuntos/gestao-publica/programas-e-projetos-degestao/apresentacao. Acesso em: 10 jul. 2014.

MPOG. Cartilha de execução do PNAGE. Informações Básicas sobre a UCE. Brasília: MPOG, 2006.

NADER, R. M. A avaliação como ferramenta para uma gestão pública orientada para resultados: o caso do Governo Federal Brasileiro. In: Congresso Internacional Del Clad, X. 2005. Disponível em: http://www.clad.org. Acesso em: 18 maio 2013.

POLLITT, C.; BOUCKAERT, G. Public management reform: a comparative analysis-new public management, governance, and the $\mathrm{Neo}$ - Weberian State. 3. ed. Oxford: University Press, 2011.

REZENDE, F. C. Por que falham as reformas administrativas? Rio de Janeiro: FGV, 2004.

SANO, H.; MONTENEGRO FILHO, J. F. As técnicas de avaliação da eficiência, eficácia e efetividade na gestão pública e sua relevância para o desenvolvimento social e das ações públicas. Desenvolvimento em questão. Ijuí: Unijuí, ano 11, n. 22, p. 35-61, jan./abr. 2013.

SIMIONE, A. A. A Modernização da gestão e a governança no setor público em Moçambique. Revista de Administração Pública. Rio de Janeiro, v. 48, n. 3, p. 551-570, mai./jun. 2014.

SUBIRATS, J. Análisis de políticas públicas y gestión pública: promesas y riesgos de una vida en común. Ekonomiaz, n. 26, p. 144-149, 1993.

TIMMERS, H. Government governance: corporate governance in the public sector, why and how? In: $9^{\text {th }}$ Fee Public Sector Conference, 2000, Netherlands. Disponível em: http://www.ecgi.org/codes/documents/public_sector.pdf. Acesso:15 jun. 2013.

VASCONCELOS, E. F. PNAGE: uma visão geral dos resultados. In: Congresso CONSAD de Gestão Pública, III. Anais eletrônicos... Brasília: CONSAD, 2010. Disponível em: 
Chagas (2018)

Gestão e Efetividade do PNAGE: A Experiência de Modernização /No Estado de Sergipe em Análise

http://www.escoladegestao.pr.gov.br/arquivos/File/Material_\%20CONSAD/paineis_III_congr esso_consad/painel_35/pnage_uma_visao_geral_dos_resultados.pdf. Acesso em: 12 jan. 2014.

YIN, R. K. Estudo de caso: planejamento e métodos. Porto Alegre: Bookman, 2005. 